\section{Accessory mitral valve tissue: An overview of clinical and practical implications}

To the Editor,

Accessory mitral valve tissue (AMVT) has been defined as an embryological remnant involving the mitral valve apparatus (1-3). Importantly, this phenomenon might be confused with other cardiac pathologies (ruptured chorda tendinea, etc.) requiring a high index of suspicion for its diagnosis (2). In their recently published case report, Sehovic et al. (1) reported a patient with AMVT involving the anterior mitral valve leaflet and presenting with severe degrees of left ventricular outflow tract (LVOT) obstruction and mitral regurgitation (MR) in a middle-aged man. In this context, we would like to comment on this case and further implications of AMVT:

First, AMVT might accompany other congenital anomalies, including ventricular septal defect (VSD), mitral supravalvular ring and subaortic membrane $(2,4)$. Therefore, we wonder whether the patient (1) had any signs of spontaneous VSD closure [thinning of the perimembranous interventricular septum (IVS), aortic regurgitation (AR)], or additional membranous or ring-like structures on echocardiogram or surgical exploration.

Second, AMVTs were classified into two morphological types on the basis of their mobility pattern: Type-1 (fixed) and type2 (mobile) $(2,3)$. The case seems to be a morphological type-2 AMVT (1). Clinically, an existing hypermobility pattern was suggested as a significant risk factor for systemic embolism in the setting of AMVT (2). Therefore, we wonder about the history of documented embolic events in the patient.

Third, our group has recently elaborated on an alternative classification of AMVTs on the basis of their anatomical sites of attachment: Type-1 (AMVTs with attachments at the supravalvular level including left atrial free wall), type-2 [AMVTs on mitral leaflets, either freely swinging (type-2A) or attached to other structures at the mitral valvular level including aortic leaflets (type-2B)], and type-3 (AMVTs with attachments at the infravalvular level including left ventricular free wall) (2). Accordingly, this patient seems to have an anatomical type-2A AMVT. Interestingly, "miniature mitral valve" is a specific form of type-2A AMVT that has its own papillary muscle and chordae tendinea (2). Therefore, we wonder whether the excised material contained chordal and papillary structures.

Importantly, AMVTs might also elicit variable degrees of MR $(1,2)$. Valvular tethering and distortion seems to be the predominant mechanism of MR (with an eccentric jet) in patients with anatomical type-1 and type-3 AMVTs (2). However, functional MR associated with systolic anterior motion (SAM) of the anterior mitral leaflet (mostly owing to the Venturi effect of LVOT gradient) seems to be more likely in those with anatomical type2A AMVT (2). Therefore, identification of a severe SAM pattern might confirm the presence of a predominant "functional MR" component, and might help determine the surgical approach (potentially favoring valve repair) in this setting. We also wonder about the presence and degree of SAM in this patient (1).

Fourth, preserving the valvular structure has been the recommended surgical strategy in patients with AMVT (2). However, this patient underwent mechanical valve replacement because of the reported technical failure to access the AMVT (1). Alternative surgical techniques might allow mitral valve repair in similar clinical scenarios. In this context, we also wonder about the degree of mitral valvular degeneration and signs of other co-existing AMVT types (potentially associated with organic MR) on surgical exploration along with histopathological examination of the excised material (this mostly exhibits non-specific findings, including varying degrees of normal and degenerated valvular tissue with infiltration of inflammatory cells and mucous degeneration) $(2,4)$.

Finally, the authors elaborated on the compensatory mechanisms regarding the late presentation of their case (1). Alternatively, we hold the opinion that age-related morphological changes (ventricular hypertrophy, sigmoid septum, etc.) might progressively heighten the previously insignificant LVOT gradient in time potentially leading to the delayed clinical presentation of AMVTs. Hence, adjunctive surgical modalities (septal myectomy, etc.), on top of AMVT excision, might be necessary to completely eliminate the LVOT gradient in certain settings.

In conclusion, AMVT has been a potentially overlooked phenomenon because of its strong analogy to other cardiac pathologies. Moreover, this phenomenon has important pathophysiological and clinical implications, largely depending on its anatomical location and associated conditions (co-existing congenital anomalies, etc.). However, there still exists an absolute necessity to further heighten clinical awareness of this interesting phenomenon.

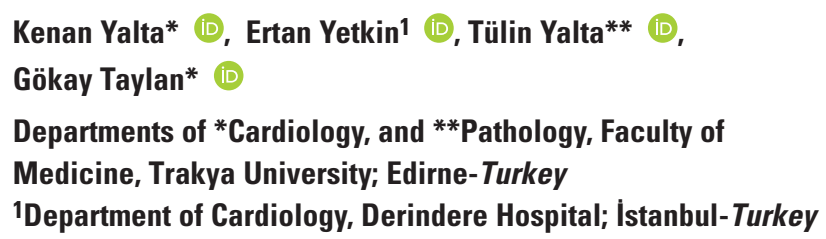

\section{References}

1. Sehovic S, Behram D, Karavdic M, Pandur S, Kacila M. Severe left ventricular outflow tract obstruction with mitral regurgitation caused by accessory mitral valve tissue in an adult: A case report. Anatol J Cardiol 2021; 25: 280-1.

2. Yetkin E, Cuglan B, Turhan H, Yalta K. Accessory mitral valve tissue: anatomical and clinical perspectives. Cardiovasc Pathol 2021; 50 : 107277.

3. Prifti E, Bonacchi M, Bartolozzi F, Frati G, Leacche M, Vanini V. Postoperative outcome in patients with accessory mitral valve tissue. Med Sci Monit 2003; 9: RA126-33. 
4. Li Y, Hu Y, Wang J, Liu L. A rare case of accessory mitral valve tissue causing left ventricular outflow tract obstruction associated with parachute mitral valve, ventricular septal defect, bicuspid aortic valve, unruptured aneurysm of aortic sinus: a case report. Eur Heart J Case Rep 2018; 2: yty082.

\section{Editor's Note}

Despite our repeated emails, we received no response from the authors.
Address for Correspondence: Dr. Kenan Yalta,

Trakya Üniversitesi Tıp Fakültesi, Kardiyoloji Ánabilim Dalı, Edirne-Türkiye

Phone: +90 5056579856

E-mail: kyalta@gmail.com, akenanyalta@trakya.edu.tr CCopyright 2021 by Turkish Society of Cardiology Available online at www.anatoljcardiol.com DOI:10.5152/AnatolJCardiol.2021.429 